\title{
Intake of and attitudes to alcohol and alcoholism
}

\section{A questionnaire survey among future doctors}

\author{
John J. Sharkey and Diana Patterson
}

\begin{abstract}
We examined the extent of alcohol misuse among final year medical students and explored their attitudes to their drinking and the drinking of others in order to goin insight into why junior doctors frequently fall to identily alcohol misusers. The questionnaire included AUDIT (Alcohol Use Disorders Investigation Test), personal detalls and an aftitudinal component. Response rate was $92 \%$. Forty-six students (37.8\%) scored as alcohol misusers. Teefotallers had a more judomental aftilude towards 'alcoholism'. Extremes of drinking behoviour among students may affect later patient care.
\end{abstract}

It has been recognised that junior doctors take inadequate alcohol histories (Barrison et al, 1980; Bell et al, 1988). Further they have a relatively low rate of detection for identifiable alcohol misuse among in-patients (Mangan \& Patterson, 1994). Various theories have been put forward to explain this. The most common areas of focus are either excessive drinking on the part of the junior doctor with a resultant skewed view of what constitutes problem drinking or an unreasonable moral stance with regard to the self-inflicted nature of alcohol related illness (Adshead \& Clare, 1986). Alcohol consumption among medical students has frequently been studied though not, as far as we know, using the AUDIT questionnaire (Saunders et al, 1993). We hoped to combine quantification of alcohol misuse with assessment of attitudes and awareness regarding alcohol and alcoholism and examine how these findings interacted with one another.

\section{The study}

The 39-item questionnaire was distributed to the entire final year medical class of Queen's University, Belfast at 10 am on Saturday 9 September 1995, with prior agreement from the faculty Dean. A brief address was made to the group explaining the nature of the study and stressing the anonymity of the answers.
Completed questionnaires were collected during coffee break.

The 39 items on the questionnaire fit broadly into four sections: (1) AUDIT; (2) detailed personal alcohol consumption and their view of their own drinking; (3) awareness of drinking in others and opinions regarding 'alcoholism' and, (4) personal data: gender, age, marital status, race, religious denomination and likely career choice.

\section{Findings}

From a class of 136, 125 (92\%) returned completed questionnaires. The average age of the students was 22.8 years, $112(91 \%)$ described themselves as 'Caucasian' and only two people were married.

\section{Alcohol consumption}

According to AUDIT scores, 22 (17.6\%) never drank alcohol, $46(37.8 \%)$ scored as alcohol misusers, with the remainder $(45.6 \%)$ drinking in moderation. Alcohol misuse was more common in females than males $(39.6 \%$ v. $34.8 \%)$. Assessment of alcohol consumption revealed that the gender-matched upper limit of low hazard was exceeded by $20(29 \%)$ men and $15(27 \%)$ women.

Of the 46 students scoring as alcohol misusers, $35(78 \%)$ reported alcohol consumption in excess of the sex-matched upper limit of low hazard. The average figure among alcohol misusers for alcohol consumption per week in units was 31.4 for males and 19.8 for females. Only one man and two women consumed a level of alcohol that fell within the 'dangerous' classification (greater than 50 and 35 units per week respectively). Thirty-six of the 46 classified their drinking as 'moderate', with only five students describing their alcohol consumption as heavy. The term moderate was used in a context that would have been better represented by 'moderately heavy'. Only $16(35 \%)$ felt it would 'be reasonable to continue at your 
current level of alcohol consumption for the next 30 years'.

\section{Awareness of and attitudes to alcohol and alcoholism}

The level of alcohol consumption per week that is considered to be the upper limit of low hazard according to the joint Royal College statement' for both men and women was correctly answered by $112(90 \%)$. When asked to describe the number of units of alcohol in a pint of lager, a local measure of spirits and a glass of table wine, $72 \%$ of the answers were correct.

The answers to the attitudinal questions were analysed according to drinking category using Mantel-Haenszel test for linear trend in proportion on SPSS.

Forty-four students (36\%) felt that 'all inpatients should be screened for alcohol misuse', however, $122(97 \%)$ felt that those identified as alcohol misusers should be offered education and advice regarding their drinking. There was no evidence that category of drinking had an association with these answers. In response to the question 'Do you feel alcoholism is a matter of personal choice?' 38 (32\%) said 'yes', with a highly significant trend through the drinking categories. The likelihood of an answer of yes' decreased with increased drinking $\left(\chi^{2}=12.00\right.$, d.f. $=1, P=0.0005)$. When faced with a choice between the following statements alcoholism is a disease', 'alcoholism is a learned behaviour' and 'anyone could become an alcoholic if they drank enough', 19 (43\%) alcohol misusers chose 'disease' compared with three (15\%) teetotallers. This trend was statistically significant $\left(\chi^{2}=6.02\right.$, d.f. $=1$, $P=0.014)$. Fifty-six students $(46 \%)$ felt 'alcoholics result in a drain on precious resources that could be better deployed elsewhere'. There was a highly significant trend displayed with this view becoming less common with increased drinking $\left(\chi^{2}=9.25\right.$, d.f. $\left.=1, P=0.002\right)$.

\section{Comments}

Queen's University in Belfast has the only medical faculty in Northern Ireland. The considerable majority of students attending are from Northern Ireland. As the ethnic spread would indicate, Northern Ireland has relatively few people from ethnic minorities in comparison to the rest of the UK. Northern Ireland is known to have a high rate of abstinence from alcohol compared with other parts of the UK. Blaney \& MacKenzie found that $50.2 \%$ of women and $23 \%$ of men were teetotal in 1978. In 1989 Sweeney et al found that $32 \%$ of women and $23 \%$ of men were abstinent. Barker et al found a female abstinence rate of $30.3 \%$ among the $16-29$ age group. These studies point to reduction over time in the rate of female abstinence although this is still very high compared with other countries. Barker et al found hazardous drinking in 29\% of men and $34.9 \%$ of women in the age group 16-29 years, using a weekly consumption of greater than 21 and 14 units of alcohol as their cut-off point. These figures are comparable to those found among the medical students. The high abstinence rate in the present study of $18 \%$ is not surprising given that the considerable majority of the students are from Northern Ireland.

\section{Limitations of the study}

There were some aspects to this study that may have led to contamination of the information. It would have been preferable to have surveyed the students at the end of their final year when they may have a better awareness of alcohol related pathology. A pilot study carried out late in the final year had a low response rate, probably due to the proximity to the finals examination. Friday night tends to be the night of heaviest alcohol consumption among Queen's students and as the survey was carried out on a Saturday morning this may have led to an over-reporting in AUDIT. The reassurance of anonymity, the spread of the answers and the impressive completion rate suggest that the collected information is probably representative for the sample.

\section{Comparative studies}

Alcohol misuse among medical students has been studied on many occasions (Firth, 1986; Collier \& Beales, 1989). The excellent study by Collier \& Beales used the CAGE questionnaire together with an estimate of alcohol consumption, however, the sample studied was biased insofar as they depended on the students to pick up. complete and return the questionnaire, resulting in a self-selecting sample. These studies estrmated the prevalence of alcohol misuse at between 4 and $23 \%$ of students. The measures used lacked the sensittvity of AUDIT which is more likely to lead to a higher rate of detection.

Opinions regarding 'alcoholism': relevance for tuition and health education

Our results show that those who drink most heavily are most likely to accept a 'disease' model of alcoholism. They are less likely to consider alcoholism as 'a matter of personal choice' and less likely to accept the statement alcoholics result in a drain in precious resources that could be better deployed elsewhere'. Extreme opinions at either pole may influence attitudes displayed to patients and may even affect the care and level of treatment offered. It is reassuring that $97 \%$ felt that those identified as alcohol misusers should 
be offered education and advice regarding their drinking', although only $36 \%$ would screen all inpatients for alcohol misuse.

\section{Conclusions}

Alcohol consumption among medical students is worryingly high with $38 \%$ of the Northern Ireland sample scoring as alcohol misusers on AUDIT. Sixty-five per cent of these had insight into their excessive alcohol consumption believing that they should not continue drinking at their current level in the long term. Drinking behaviour among the students appeared to influence their attitude to concepts such as whether alcoholism was a disease, whether it was a matter of personal choice and whether treatment of alcoholics diverted precious resources from elsewhere.

\section{Acknowledgements}

I would like to thank Dr Chris Patterson for his invaluable statistical input. I would further like to thank the final year medical students of Queen's University Belfast for their cooperation.

\section{References}

ADSHEAD, F. \& ClARE, A. (1986) Doctors' double standards on alcohol. British Medical Joumal, 293. 1590-1591.

BARKER, M. E., MCLEAN, S. I., MCKENNA, P. G., et al (1988) Diet, Lifestyle and Health in Northern Ireland. A Report to the Health Promotion Research Trust. Untversity of Ulster: Centre for Applied Health Studies.
BARRISON, I., VIOLA, L. \& LYON, I. M. (1980) Do housemen take an adequate drinking history? British Medical Journal, 281, 1040.

BEU, J., THE, E., PATEL, A., et al (1988) Detection of at risk drinking in a teaching hospital. Medical Journal of Australia, 149, 351-355.

BLANEY, R. \& MACKENZE, G. (1978) A Northern Ireland Community Health Study: Report to the Department of Health and Social Services. Queen's University Belfast: Department of Community Medicine.

COLLIER, D. J. \& BEALES, I. L. P. (1989) Drinking among medical students: a questionnaire study. British Medical Journal, 288, 19-22.

FIRTH, J. (1986) Levels and sources of stress in medical students. British Medical Journal, 292, 1177-1180.

Mangan, B. G. \& Patrerson, D. G. (1994) The prevalence of alcohol dependence syndrome in a rural general hospital in Northern Ireland. Irish Journal of Psychological Medicine, 11, 73-75.

SAUNDERS, J. B., AASLAND, O. G., BABOR, T. F., et al (1993) Development of the Alcohol Use Disorders Identification Test (AUDIT): WHO Collaborative Project on early detection of persons with harmful alcohol consumption-II. Addiction, 88, 791-804.

SWEENEY, K., GILlaN, J. \& ORR, J. (1990) Drinking Habits in Northern Ireland. Department of Health and Social Services for Northern Ireland 1987-1989. Northern Ireland: HMSO.

* John J. Sharkey, Senior Registrar, Knockbracken Healthcare Park, Saintfield Road, Belfast BT8 8BH; and Diana G. Patterson, Consultant Psychiatrist, Shaftesbury Square Hospital, 116120 Great Victoria Street, Belfast BT2 7BW

*Correspondence 